\title{
Docência universitária na formação de profissionais dinâmicos: ampliando 0 potencial da profissão em biblioteconomia
}

\author{
Jorge Santa Anna*
}

Artículo recibido:

14 de febrero de 2019

Artículo aceptado:

3 de junio de 2019

Artículo de investigación
Resumo

A docência universitária proporciona contribuições em diversos sentidos, sobretudo por garantir a formação profissional demandada pela sociedade. $\mathrm{O}$ objetivo deste estudo é apresentar os resultados alcançados por meio de estratégias e métodos inovadores adotados na condução da disciplina Fontes de Informação, do Curso Superior de Biblioteconomia. Para tanto, recorreu-se à pesquisa bibliográfica - por meio da consulta a livros e artigos - e pesquisa de campo, a partir da observação a uma experiência realizada. A reformulação das estratégias e metodologias de ensino com base no diálogo, compartilhamento, pesquisa

* Universidade Federal de Minas Gerais (UFMG), Brasil jorja020@yahoo.com.br

INVESTIGACIÓN BIBLIOTECOLÓGICA, vol. 34, núm. 82, enero/marzo, 2020, México, ISSN: 2448-8321 pp. 13-28 
e na investigação prática demonstraram mudanças de comportamentos, concepções e atitudes, além do engajamento, satisfação, motivação e comprometimento do alunado para com as atividades desenvolvidas. Com efeito, essas reformulações pautadas na inovação e na criatividade representaram uma estratégia, haja vista formar profissionais dinâmicos, que reconheçam o potencial da profissão, de modo a atuar em diversos segmentos profissionais, atendendo as demandas da sociedade.

Palavras-chave: Docência Universitária; Docência em Biblioteconomia; Ensino pela Pesquisa; Diálogo e Compartilhamento; Formação Profissional em Biblioteconomia

La docencia universitaria en la formación de profesionales dinámicos: amplía el potencial de la profesión en biblioteconomía

Jorge Santa Anna

\section{RESUMEN}

La docencia universitaria aporta contribuciones en diversos sentidos, sobre todo al garantizar la formación profesional que demanda la sociedad. El objetivo de este estudio es presentar los resultados alcanzados por medio de estrategias y métodos innovadores adoptados en la conducción de la disciplina Fuentes de Información, del Curso Superior de Biblioteconomía. Para ello se recurrió a la investigación bibliográfica -por medio de la consulta de libros y artículos- y a la investigación de campo, a partir de la observación de una experiencia realizada. La reformulación de las estrategias y metodologías de enseñanza basadas en el diálogo, el compartir, la investigación y la investigación práctica ha demostrado cambios en el comportamiento, las concepciones y las actitudes, además del compromiso, la satisfacción, la motivación y el involucramiento del alumnado con las actividades desarrolladas. En efecto, esas reformulaciones pautadas en la innovación y la creatividad representan una estrategia que apunta a la formación de profesionales dinámicos que reconozcan el potencial de la profesión para actuar en diversos segmentos profesionales, al mismo tiempo que se atienden las demandas de la sociedad. 
Palabras clave: Docencia Universitaria; Docencia en Biblioteconomía; Enseñanza por la Investigación; Diálogo y Compartición; Formación Profesional en Biblioteconomía

University teaching in the training of dynamic professionals: expanding the potential of profession in librarianship

Jorge Santa Anna

\section{Abstract}

University teaching provides contributions in several senses, especially in guaranteeing the professional training demanded by society. The objective of this study is to present the results achieved through innovative strategies and methods adopted in the course of the discipline Sources of Information, of the Superior Course of Librarianship. In order to do so, we resorted to bibliographical research -through the consultation of books and articles- and field research, from observation of an experience carried out. The reformulation of teaching strategies and methodologies based on dialogue, sharing, research and practical research demonstrated visible changes in behavior, conceptions and attitudes, in addition to the engagement, satisfaction, motivation and commitment of the student to the activities developed. In fact, these reformulations based on innovation and creativity represented a strategy, in view of training dynamic professionals, who recognize the potential of the profession for acting in several professional segments, and simultaneously meeting the demands of society.

Keywords: University Teaching; Teaching in Librarianship; Teaching by Research; Dialogue and Sharing; Professional Training in Library Science

\section{INTRODUÇÃO}

s atividades que permeiam o fazer educativo nas instituições de ensino
diperior envolvem um conjunto de procedimentos dos mais variados,
direcionados, sobremaneira, a atender as bases sustentadoras dessas ins-
tituições, o ensino, a pesquisa e a extensão. Ser docente em universidades 
constitui uma tarefa árdua, pois além de atender esses pilares, a prática educativa tem o propósito de formar profissionais competentes que assegurem a qualidade dos serviços prestados por uma profissão, junto à sociedade.

Além disso, a docência universitária perpassa por diversos desafios, sobretudo no que tange à ausência de capacitação e inovação do docente universitário (Severino, 2008). Em concordância com Severino (2008) está Junges e Behrens (2015: 285, grifo nosso), para quem o professor universitário precisa, constantemente, como qualquer profissional, se reinventar, despertando motivação e engajamento dos alunos para com as atividades educativas. Assim, o professor precisa, primordialmente, “[...] olhar para sua prática pedagógica, interpretá-la e recriá-la, tornando-a também uma fonte de aprendizagem numa perspectiva de mudança e de inovação".

Com efeito, acredita-se que essas estratégias de inovação e criatividade devem permear o fazer docente nas universidades. Caberá ao docente adequar o plano de ensino conforme proposta bem definida, com base no atendimento das exigências da instituição e das necessidades dos alunos, promovendo satisfação dos alunos, por conseguinte, viabilizando o ensino-aprendizagem e uma efetiva capacitação dos futuros profissionais.

Embora essas estratégias estejam imbricadas à pessoa do docente, muitos métodos e técnicas de ensino são estabelecidos pelas próprias áreas de conhecimento. Dentre esses métodos, grande contribuição tem sido alcançada por meio da prática da pesquisa, em que a disciplina ministrada seja conduzida por momentos de investigação. Para Emmel e Krul (2017: 44, grifo nosso), "as marcas das trajetórias de formação e identidade docentes fazem compreender o ser professor vinculado ao ser pesquisador, entendendo que o fazer docente se dá por meio de investigações e pesquisas [...]”.

Além da pesquisa nas salas de aula das universidades, a prática docente precisa ser conduzida por relações dialógicas entre os envolvidos, em que o professor se comporte como um mediador, ensinando e, ao mesmo tempo, aprendendo com o alunado. Sendo assim, o docente precisa motivar os alunos a participarem das aulas, conduzindo as atividades de forma harmoniosa com seus discentes, compartilhando conhecimento com eles. Em suma, “[...] toda prática educativa demanda a existência de sujeitos, um que, ensinando, aprende, outro que, aprendendo, ensina [...]" (Freire, 2006: 28).

Atrelado a essas necessidades de capacitação e inovação por parte dos docentes universitários, também é importante destacar a fusão entre teoria e prática, de modo que o fazer profissional seja vivenciado pelos alunos ainda no decurso da formação acadêmica. Assim, elimina-se a "solidão pedagógica”, em que as atividades curriculares possam estar "[...] em sintonia com a dinâmica social e [provoquem] clareza do perfil de profissionais que tem 
sido demandado pela sociedade e pelo mundo do trabalho" (Garcia e Silva, 2017: 75).

A partir dessa contextualização, objetiva-se apresentar os resultados alcançados por meio da adoção de estratégias e métodos inovadores adotados na condução da disciplina Fontes de Informação, ministrada em um Curso Superior de Biblioteconomia de uma universidade pública.

Enfatiza-se que as atividades adotadas foram planejadas considerando o método de compartilhamento de conhecimentos e relações dialógicas e harmoniosas estabelecidas entre alunos e professor (Freire, 2001, 2006), como também a prática da pesquisa (Freire, 2006; Emmel e Krul, 2017) e, atrelado a esses procedimentos, utilizaram-se investigações in loco, de modo a fundir teoria e prática (Garcia e Silva, 2017) e, dessa forma, reconhecer a realidade do mercado e despertar a ampliação dos potenciais da profissão de bibliotecário.

\section{Metodologia}

Metodologicamente, adotou-se, neste estudo, a pesquisa bibliográfica e de campo. A primeira caracteriza-se pelo levantamento e análise a diversas fontes de informação publicadas na literatura, e a segunda como análise e aprofundamento de uma realidade específica, normalmente conduzida pela técnica da observação, como apontado no estudo de Gil (2010).

No que tange à pesquisa bibliográfica, para este artigo, recorreu-se, primeiramente, à reflexão sobre a prática docente nas universidades, focando no papel do docente e a necessidade de mudanças nessa prática em face das transformações que acometem a universidade, a sociedade e o mercado de trabalho. A análise à literatura sobre esse assunto, realizada em livros e artigos científicos, permitiu identificar diversas reflexões, sobretudo no que tange à necessidade de o docente elaborar as atividades disciplinares, pautadas em métodos inovadores que contemplem a ação do diálogo, do compartilhamento, da pesquisa e da investigação à realidade profissional.

Munido desse arcabouço teórico, realizou o estudo de campo, em que o pesquisador/professor/autor reformulou os procedimentos metodológicos e atividades discentes da disciplina Fontes de Informação, conduzindo a disciplina com atividades que contemplaram as questões identificadas na literatura sobre as estratégias e métodos inovadores por parte dos docentes universitários.

Este estudo também se caracteriza como descritivo, de natureza qualitativa, uma vez que descreve dados acerca da realidade investigada - qual seja, o lecionamento da disciplina Fontes de Informação - sem representar numericamente esses dados (Goldenberg, 1999). Também se utilizou da técnica 
da observação, com base nas modificações realizadas na disciplina e os rendimentos e comportamentos observados ao longo da disciplina, tanto pelo professor/pesquisador/autor quanto pelos alunos.

Sendo assim, no decorrer da disciplina, o professor registrou os procedimentos e as atividades realizadas, como também o comportamento dos alunos, sendo possível apresentar os resultados alcançados a partir da vivência prática na sala de aula. Os resultados e suas discussões sobre essa experiência docente estão apresentados a seguir.

\section{Resultados}

A disciplina Fontes de Informação é ofertada no quinto período do Curso de Biblioteconomia e possui - conforme plano de ensino aprovado pelo Departamento do Curso - como principais temas contemplados: 1. conceituação e análise de fontes bibliográficas gerais e especializadas; 2 . técnicas de levantamento bibliográfico; 3 . bibliografia brasileira; e, por fim, 4. controle bibliográfico universal.

Essa disciplina possui uma natureza meramente teórica, em que o alunado capacita-se a identificar e compreender as características das diversas fontes de informação, os ambientes de armazenamento dessas fontes e o fluxo editorial de produção e publicação desses documentos. De acordo com a ementa da referida disciplina, seus objetivos são proporcionar ao alunado: 1. entender noções básicas da comunicação científica; 2. saber definir as fontes de informação, segundo sua categoria e tipologia; 3. desenvolver a reflexão crítica das necessidades, dos canais de acesso e do uso das fontes de informação; 4. conhecer as políticas de acesso à informação; 5. identificar os instrumentos de recuperação das fontes de informação; 6. depreender o conceito de rede e sua utilização na busca de fontes de informação; e 7. compreender a importância do controle bibliográfico.

Salienta-se que, os dados até aqui descritos, acerca da ementa e dos objetivos da disciplina, não foram modificados a partir das reflexões propostas na literatura, haja vista que essas reflexões relacionaram à forma como esses conteúdos e ações foram transmitidos aos alunos, ou seja, as reflexões teóricas impactaram nos procedimentos metodológicos adotados para transmitir o conhecimento requerido na disciplina.

A fim de facilitar a condução dos assuntos ao longo da disciplina, o plano de ensino estava dividido em três unidades, a saber: unidade I: Introdução às fontes de informação; unidade II: Fluxo da informação; e unidade III: Tecnologias da informação. Destaca-se que os conteúdos contidos nessas unidades 
contemplavam aspectos relativos a princípios, leis, teorias, conceitos e características das fontes de informação, fluxo e tecnologias da informação.

Tendo como base a discussão proposta por Pereira (2015) e Garcia e Silva (2017), sobre a importância de se abordar na sala de aula reflexões que promovam a ampliação da prática profissional, haja vista seu melhor aproveitamento, percebeu-se a necessidade de acrescentar ao plano tópicos que proporcionassem o debate sobre o potencial dos profissionais ao atuar na gestão das fontes de informação.

Sendo assim, a unidade III intitulou-se Tecnologias da informação e possibilidades de atuação profissional, cuja intenção desse acréscimo foi demonstrar e conscientizar os futuros profissionais acerca dos novos campos de atuação para os bibliotecários em face do conhecimento que adquiriram para gerenciar as fontes de informações existentes na sociedade.

A própria literatura básica da disciplina apresenta obras que demonstram esse potencial a ser descoberto pelo bibliotecário, de modo que ele passe a atuar em outros contextos que extravasam a atuação técnica apenas em bibliotecas. Para Rodrigues e Crespo (2006), o bibliotecário pode atuar com fontes de informação de qualquer tipo, em qualquer suporte, selecionando-as e adequando-as de acordo com as necessidades do seu usuário. Portanto, para as referidas autoras, o profissional precisa "[...] descobrir novos caminhos e, partindo-se de uma análise crítica, refletir sobre os serviços oferecidos, avaliar novos serviços potencialmente interessantes e, desta forma, colocar-se, agir e atuar como o intermediário do conhecimento" (Rodrigues e Crespo, 2006: 13, grifo nosso).

No que se refere aos procedimentos metodológicos para condução da disciplina (atividades discentes e docente) foram realizadas algumas inserções, de modo a consolidar a sala de aula como um ambiente de interação e com clima democrático e harmonioso estabelecido entre professor e alunado. Os acréscimos realizados, em grande parte, tiveram o intuito de despertar/motivar os alunos ao diálogo, à prática da pesquisa e ao compartilhamento de conhecimento, de modo que todos se sentissem como participantes do processo de ampliação de conhecimento, como apontado, com mais intensidade, nas obras de Demo (2001), Freire (2006), Emmel e Krul (2017) e David (2017). O Quadro 1 demonstra as mudanças incrementadas nas atividades desenvolvidas na unidade I da disciplina.

\begin{tabular}{|c|c|}
\hline \multicolumn{2}{|c|}{ Unidade I: Introdução às fontes de informação } \\
\hline Procedimentos já existentes na disciplina & Acréscimos realizados pelo docente \\
\hline Aulas expositivas e debates & $\begin{array}{l}\text { Discussão em grupo de textos diferentes e sociali- } \\
\text { zação por meio de rodas de conversa }\end{array}$ \\
\hline
\end{tabular}




\begin{tabular}{|c|c|}
\hline Leitura e fichamento de textos & $\begin{array}{l}\text { Visita técnica ao acervo de uma biblioteca, de um } \\
\text { arquivo e de um museu }\end{array}$ \\
\hline $\begin{array}{l}\text { Demonstração dos recursos de tecnologia da infor- } \\
\text { mação aplicados às unidades de informação, através } \\
\text { da pesquisa em catálogos e bases de dados }\end{array}$ & Resenha e relatório científico das visitas técnicas \\
\hline
\end{tabular}

Quadro 1. Procedimentos metodológicos, com foco nas atividades desenvolvidas na unidade I Fonte: dados da pesquisa (2017)

Por meio da análise ao Quadro 1, é possível identificar que os acréscimos realizados, em grande parte, foram oriundos das discussões teóricas sobre a importância e necessidade em se promover, na sala de aula, um ambiente de diálogo e interação, de modo que o conhecimento adquirido a partir da leitura aos textos pudesse ser compartilhado em mão dupla, em que todos atuaram, ora como ensinantes, ora como aprendizes, como recomendado por Freire (2006).

Os procedimentos adotados, especificamente, no que tange à leitura de textos em grupo e a devida socialização promoveram segurança aos discentes e treinamento das habilidades em oratória. Ao professor, percebe-se a ruptura da concepção centralizadora, em que o domínio do conhecimento estivesse apenas, nele. Na verdade, o professor atuou como mediador dos debates.

A função do professor é a de facilitar a participação de todos e de cada um no fórum de trocas simbólicas em que a aula deve transformar-se; oferecer instrumentos culturais de maior potencialidade explicativa (que enriqueçam o debate) e provocar a reflexão sobre as próprias trocas e suas consequências para o conhecimento e para a ação. (Emmel e Krul, 2017: 50)

Outro acréscimo nos procedimentos de ensino diz respeito a uma atividade prática, conduzida por meio de visita em três diferentes unidades de informação, cujo objetivo dessas visitas foi demonstrar aos alunos a diversidade de fontes de informação que existem nos diferentes acervos informacionais da sociedade. A análise ao relatório técnico elaborado pelos discentes permitiu constatar o quanto eles mesclaram a teoria discorrida na sala de aula e a realidade vivenciada pelos profissionais que atuavam nas unidades visitadas.

Percebeu-se, então, a valiosa contribuição em entrosar teoria e prática, sobretudo pela motivação, engajamento e satisfação dos discentes com as atividades realizadas. As discussões dos textos, seguido das visitas técnicas e da elaboração da resenha e relatório demonstraram aos discentes o quanto a disciplina sustentou-se na dinamicidade e diversidade, caracterizando-se como uma disciplina inovadora, evitando, assim, manifestar práticas monótonas de ensino. Para Junges e Behrens (2015: 310, grifo nosso), 
[...] a docência universitária numa perspectiva inovadora, que entende o professor como agente social, o aluno como cidadão crítico e a instituição educativa como campo de produção do conhecimento, exige um comprometimento com a aprendizagem, ao longo de toda a vida, num movimento dinâmico de mudança, de ação-reflexão-ação e de articulação da teoria e da prática.

Semelhante à unidade I da disciplina Fontes de Informação, na unidade II, o acréscimo realizado também contemplou questões relativas ao ambiente dialógico, integrado e participativo, em que pese atividades de leitura, debates socializados por grupos e escritas de textos científicos. No entanto, o diferencial está na prática da pesquisa teórica, em que os alunos elaboraram seminário sobre temas específicos e, para tanto, recorreram à busca e seleção de artigos e livros para embasar as reflexões apresentadas. O Quadro 2 ilustra os acréscimos aferidos a essa unidade.

\begin{tabular}{|c|c|}
\hline \multicolumn{2}{|c|}{ Unidade II: Fluxo da informação } \\
\hline Procedimentos já existentes na disciplina & Acréscimos realizados pelo docente \\
\hline Aulas teóricas e práticas & $\begin{array}{l}\text { Levantamento bibliográfico sobre temas } \\
\text { específicos por grupos }\end{array}$ \\
\hline Leitura e fichamento de textos & $\begin{array}{l}\text { Apresentação dos temas por grupos em } \\
\text { forma de seminário }\end{array}$ \\
\hline Leitura de textos e estudos dirigidos em grupo & $\begin{array}{l}\text { Relatório técnico e acadêmico das atividades } \\
\text { realizadas pelos grupos }\end{array}$ \\
\hline
\end{tabular}

Quadro 2. Procedimentos metodológicos, com foco nas atividades desenvolvidas na unidade II Fonte: dados da pesquisa (2017)

As atividades desenvolvidas ao longo da unidade II, sobretudo no que tange à pesquisa teórica para sustentar a montagem do seminário pelos grupos e a elaboração do relatório sobre o seminário permitem identificar que os alunos desenvolveram ações de autonomia, senso crítico e capacidade para planejar, controlar, enfim, gerenciar suas atitudes, a fim de atingir o objetivo almejado com sucesso, como apontado por Freire (2001) e Demo (2001).

Com efeito, para que as atividades fossem bem-sucedidas, o professor explanou sobre as técnicas de levantamento bibliográfico, como também demonstrou a necessidade de os alunos saberem contextualizar os assuntos, comparando-os ao levantar as fontes, direcionar as discussões no seminário e sistematizar as ideias no texto que elaboraram. Nesse sentido, alunos e professores precisam "[...] transpor os limites das disciplinas divididas cartesianamente, atuando de forma interdisciplinar, com métodos globalizados, trabalhando com seminários, projetos, conteúdos contextualizados, com uma avaliação formativa, por portfólio, entre outros [...]" (Junges e Behrens, 2015: 301). 
Importante salientar o espírito investigativo, crítico e interventor dos alunos ao terem autonomia de preparar os seminários. Assim, nas salas de aulas das universidades, "[...] deveria impor-se a atitude de aprender pela elaboração própria, substituindo a curiosidade de escutar pela de produzir [...]” (Demo, 2001: 10), e munidos de senso crítico e reflexivo, alunos e professores participam de uma prática educativa que não se prende "[...] apenas à leitura da palavra, à leitura do texto, mas também à leitura do contexto, à leitura do mundo" (Freire, 2006:30).

Por fim, na unidade III, o acréscimo realizado nos procedimentos metodológicos da unidade permitiu a criação, pelo professor, de uma atividade prática, com um cunho investigativo mais intenso, de modo a despertar nos alunos, o conhecimento da realidade do mercado, e, por outro lado, o reconhecimento de novos campos de atuação do profissional. O Quadro 3 explana os procedimentos da unidade III.

\begin{tabular}{|c|c|}
\hline \multicolumn{2}{|c|}{ Unidade III: Tecnologias da Informação e possibilidades de atuação profissional } \\
\hline Procedimentos já existentes na disciplina & Acréscimos realizados pelo docente \\
\hline Leitura e resenhas de textos & $\begin{array}{l}\text { Estudo de campo em grupo realizado a } \\
\text { profissionais }\end{array}$ \\
\hline $\begin{array}{l}\text { Uso prático de computador no manuseio de diferentes fontes } \\
\text { de informação }\end{array}$ & $\begin{array}{l}\text { Apresentação dos dados coletados na } \\
\text { forma de roda de conversas }\end{array}$ \\
\hline $\begin{array}{l}\text { Visitas a bibliotecas, repositórios, portais, dentre outras fontes } \\
\text { por meio do uso de computador }\end{array}$ & Relatório do estudo de campo \\
\hline
\end{tabular}

Quadro 3. Procedimentos metodológicos, com foco nas atividades desenvolvidas na unidade III Fonte: dados da pesquisa (2017)

O estudo de campo realizado na unidade III contemplou a aplicação de um questionário elaborado pelo docente, com perguntas abertas, tendo os grupos que entrevistarem um bibliotecário atuante na área de Biblioteconomia, independente do segmento ou atuação profissional. O Quadro 4 sistematiza as perguntas norteadoras para coleta de dados pelos discentes. 


\begin{abstract}
- Qual sua formação profissional? Após a graduação, você tem feito algum curso específico? Quais?
- Atualmente, você está vinculado a alguma instituição (empresa/biblioteca/centro de documentação) ou está trabalhando de forma autônoma? Acredita que o bibliotecário pode atuar no mercado de forma autônoma? 0 bibliotecário pode ser empreendedor, a seu ver?

- No seu fazer cotidiano, quais fontes de informação (livros, periódicos, multimeios etc.) você utiliza?

- Você tem aproveitado as potencialidades da internet a fim de ampliar o seu fazer, atuando em outros segmentos, fora da instituição onde atua, a fim de melhorar sua renda?

- Além das fontes de informação convencionais (livros, periódicos, multimeios), na sua opinião, os bibliotecários podem atuar junto a outras fontes de informação? Como isso poderia acontecer?

- Com o surgimento de novos formatos de documentos, os chamados documentos digitais, e com os novos canais de disseminação da informação oriundos com o avanço da internet, como ficará o trabalho do bibliotecário?

- Acredita que o bibliotecário possui competências para atuar na organização da informação existente nas empresas? Ou ele é preparado, apenas, para atuar nas bibliotecas?

- É fato que a grande maioria dos bibliotecários atua em bibliotecas"! A seu ver, essa realidade acontece porque os empresários não conhecem as potencialidades da profissão ou porque o próprio profissional não divulga, não se capacita e não demonstra suas competências?
\end{abstract}

Quadro 4. Questionário para investigação in loco demandado na unidade III

Fonte: dados da pesquisa (2017)

A leitura ao Quadro 4 permite aludir que o objetivo dessa atividade era, além de desenvolver a habilidade de pesquisa, realizar uma investigação na realidade prática do mercado, considerando as possibilidades de campos de atuação dos bibliotecários e o reconhecimento desses profissionais quanto a suas potencialidades, sobretudo quanto ao uso das diferentes modalidades de fontes de informação.

Assim como defende Rodrigues e Crespo (2006), acerca das diversas possibilidades de atuação do bibliotecário no mercado de trabalho, podendo atuar em ambientes além das bibliotecas, Figueiredo e Souza (2007: 18, grifo nosso) demonstram que o mercado é heterogêneo, com múltiplas demandas e está em transformação. Essa tendência da realidade se justifica "[...] porque todos os setores da economia atualmente precisam de profissionais que saibam lidar e organizar todos os tipos de informação".

Os dados coletados in loco foram apresentados por meio de rodas de conversa, no último dia da disciplina. ${ }^{1}$ Em linhas gerais, por meio da diversidade de respostas obtidas, identificou-se a ausência de profissionais atuando no tratamento de fontes de informação, de forma autônoma e, quando constatada essa atuação, a maioria dos profissionais exerce atividades no setor de

1 Ressalta-se que, após realização das atividades disciplinares, esses dados foram sistematizados e estão sendo interpretados, com maior detalhamento e aprofundamento sob a perspectiva de atuação profissional junto ao mercado de trabalho. Esses procedimentos viabilizaram a necessidade de se planejar uma pesquisa futura, a qual ainda se encontra em fase de elaboração. 
processamento técnico de bibliotecas, muitos deles vinculados por meio de concurso público.

Outro resultado interessante constatado nas respostas coletadas foi o fato de que, a grande maioria dos profissionais considerou promissor o campo de atuação no tratamento e gestão de fontes de informação, principalmente quanto à seleção de fontes, orientações, revisões e normalizações em trabalhos científicos; no entanto, não se mostraram motivados a se adequar para atuar nesse segmento, tendo como foco maior, ainda, exercer funções diferenciadas nos serviços das bibliotecas e arquivos.

Embora constatou-se a não ocupação desse segmento profissional por parte dos entrevistados (em algumas respostas manifestou-se até o descaso por parte do entrevistado), é importante considerar o potencial desse campo de atuação, conforme demonstram inúmeros estudos da literatura. Esse campo de atuação tende a crescer, sobremaneira, com o nascimento das fontes de informação eletrônicas, tal como blogs, repositórios, portais, dentre outras, como demonstrado na obra de Tomaél (2008).

Além da necessidade em se analisar e identificar as fontes eletrônicas, permitindo um melhor tratamento e armazenamento, faz-se necessário, também, reconhecer critérios que possam avaliar a qualidade dessas fontes, tendo em vista permitir um melhor aproveitamento, com base nas necessidades dos usuários (Tomaél e Valentim, 2004). Também é destacado na literatura o potencial do bibliotecário em analisar e avaliar sites institucionais, de modo que esse profissional possa inserir-se no campo da elaboração e gestão dessas páginas eletrônicas (Baptista, 2004).

Mesmo diante da constatação de que os entrevistados não atuam no campo do tratamento e gestão das fontes de informação, as reflexões propostas pela literatura em consonância com os argumentos defendidos pelo professor, ao longo da disciplina - sobre a necessidade de expansão dos campos de atuação do bibliotecário - foram suficientes para despertar nos alunos os potenciais da profissão e a necessidade de eles mesmos ocuparem essas demandas requeridas pela sociedade, bastando, para tanto, se capacitarem, e adotarem uma postura interventiva, audaciosa e empreendedora.

A finalidade de os alunos desenvolverem essa atividade de investigação em meio à realidade do mercado evidencia o quanto inquieta o docente o fato de perceber que muitos bibliotecários não ocupam os postos de trabalho a eles destinados (atuando apenas nas tradicionais bibliotecas, em meio a procedimentos técnicos), o que provoca a ocupação desses postos por profissionais de outras áreas. Promovendo uma atividade dessa natureza, certamente o docente inovou a prática docente, com intuito de formar profissionais dinâmicos, por conseguinte, ampliando o potencial da profissão de Biblioteconomia. 
Essa atitude em mesclar teoria e prática e realizar investigações na realidade do mercado constitui um diferencial à prática docente, pois, dessa forma, acredita-se que, o professor tendo ou não consciência, sua ação em sala de aula é uma ação de formação do homem, do profissional e do cidadão, e por isso, é uma ação que ultrapassa a sala de aula (Pereira, 2015).

Em concordância com Pereira (2015), enfatiza Garcia e Silva (2017: 70) os benefícios oriundos com atividades investigativas e integradoras no âmbito do ensino universitário, pois tais atividades consolidam-se como "[...] estratégia qualificada à formação de profissionais, por meio de ações pedagógicas compartilhadas que, além de favorecer a aprendizagem, envolve a comunidade acadêmica [...]". Ademais, reforçam que, iniciativas nesse sentido tendem a reduzir a solidão pedagógica existente entre pares, colocando docentes e alunos " $[. .$.$] em sintonia com a dinâmica social e com o perfil de profissionais$ e cidadãos demandados pela sociedade contemporânea, já que possuem conhecimentos e atitudes necessários para transformá-la [...]” (Garcia e Silva, 2017: 70, grifo nosso).

As atividades educativas adotadas pelo docente podem ser caracterizadas como metodologias de aprendizagem por objetivos, visto que tinham o propósito de atender um plano disciplinar formalizado. Nesse caso, os resultados da metodologia adotada no desenvolvimento das atividades de ensino eram previsíveis, considerando o propósito formulado na disciplina. No entanto, esses propósitos, ao serem concretizados, por meio do aprendizado e da formação propiciada aos alunos, possibilitaram a concretização da metodologia por competências.

Portanto, a metodologia por competências também se manifestou visto que os alunos foram instigados a reconhecer outras formas de atuação do profissional, no tratamento e na gestão das fontes de informação, tornando-se mais capacitados a reconhecer os nichos de trabalho e as oportunidades existentes.

Acerca dessa abordagem de ensino, Marinho-Araujo e Rabelo (2015: 448) reforçam que trata de uma concepção ampla, pois não são considerados, apenas, “[...] aspectos racionais, cognitivos ou mentais, mas também processos intersubjetivos, afetivos, socioculturais [...]”. Essa capacidade profissional se faz necessária, sobretudo “[...] em um cenário no qual as subjetividades perpassam processos educativos e por eles são transformados” ( $\mathrm{Ma}$ rinho-Araujo e Rabelo, 2015: 448).

Ao centrar-se na abordagem por competências, o ensino universitário vai muito além da transmissão de conhecimentos teóricos, pois garante o fortalecimento do profissional, o qual tem a possibilidade de ampliação, de integração e de complementação do que lhe é transmitido nas salas de aula, 
a partir do valor de uso desse conhecimento em uma determinada ação demandada pelo mercado (Bunk, 1994).

Ter competências profissionais é um exercício adquirido no processo formativo que precisa ser conjugado com a realidade do mercado. Assim, o papel principal da atuação docente e formativa é possibilitar a autonomia do sujeito, capacitado a utilizar os recursos que lhe são disponibilizados, reconhecer as necessidades das organizações e dos indivíduos, e, a partir da competência em informação, propor ações de melhoria à sociedade (Bunk, 1994).

Em suma, os resultados oriundos da experiência no lecionamento da disciplina Fontes de Informação e apresentados neste texto demonstram o quanto a docência universitária pode se transformar e contribuir para a adequação dos profissionais no mercado, principalmente quando eles são regidos, durante a formação acadêmica, por métodos e estratégias inovadoras, em que ultrapassem "[...] o paradigma conservador baseado na reprodução do conhecimento, na repetição e na memorização [...]” (Behrens, 2011: 466). Cabe, portanto, a reflexão e conscientização de todos os envolvidos com a prática educativa nas universidades, quanto à necessidade de melhoria contínua das práticas formativas que permeiam essas instituições.

\section{CONSIDERAÇÕES FINAIS}

Este texto apresentou reflexões teóricas e relatos oriundos de experiência docente, promovendo provocações acerca das vantagens para as profissões e para a sociedade, de um modo geral, a respeito de uma formação acadêmica conduzida por estratégias e metodologias inovadoras e criativas a serem adotadas no âmbito da docência universitária.

Percebeu-se que a literatura até então produzida sobre docência no ensino superior é abrangente, contemplando diferentes aspectos, enfoques e perspectivas de estudo, sobretudo no que tange ao papel desempenhado pelo docente, haja vista romper a concepção tradicionalista de ensino - pautada na repetição e postura centralizada do professor - para consolidar a concepção compartilhada, investigativa e interventiva na prática educativa.

Reformular as estratégias e metodologias de ensino torna-se uma necessidade inquietante e contínua, o que amplia, cada vez mais, os procedimentos de ensino que norteiam a prática educativa do docente universitário em diversas áreas de conhecimento. No entanto, não se pode esquecer das valiosas contribuições quando se propaga, na sala de aula, um ambiente que permeie o diálogo, o compartilhamento, a pesquisa e a investigação prática. 
Por meio da adoção dessas estratégias ao reformular a disciplina Fontes de Informação, especificamente, os resultados da prática docente conduzida nessa disciplina demonstraram mudanças de comportamentos, concepções e atitudes, além do engajamento, satisfação, motivação e comprometimento do alunado para com as atividades desenvolvidas.

Além desses benefícios proporcionados aos discentes, também foi possível perceber que os discentes identificaram os potenciais do bibliotecário e a adequação desse profissional à realidade do mercado, de modo a ocupar os postos de trabalhos demandados. Com efeito, reformular as práticas educativas, por meio da inovação e da criatividade, representa uma estratégia do docente universitário, haja vista formar profissionais dinâmicos e reconhecedores de sua missão para melhoria da sociedade.

Conhecer as discussões teóricas a respeito da docência universitária e inseri-las na realidade prática das instituições de ensino superior, certamente, acarretarão benefícios em diversos aspectos - como promoveram na reformulação da disciplina relatada neste artigo. Portanto, a análise a outros fatores inerentes a essa disciplina, tal como o processo avaliativo dos discentes e os recursos pedagógicos utilizados na condução das aulas representam indicações para a realização de futuros estudos.

\section{REFERÊNCIAS}

Baptista, Sofia Galvão. 2004. “As oportunidades de trabalho existentes na Internet na área de construção de páginas de unidades de informação: discussão sobre as ideias divulgadas na literatura", in Profissionais da Informação, organizado por Sofia Galvão Baptista e Suzana Pinheiro Machado Mueller, 224-241. Brasília: Thesaurus.

Behrens, Marilda Aparecida. 2011. "Docência universitária: formação ou improvisação?”. Educação 36 (3): 441-454.

https://periodicos.ufsm.br/reveducacao/article/view/2976/2423

Bunk, Gerhard P. 1994. "La transmisión de las competencias en la formación y perfeccionamiento profesionales en la RFA". Revista CEDEFOP 1 (1): 16.

http://www.scielo.br/scielo.php? script=sci_nlinks\&ref=000211\&pi$\mathrm{d}=$ S0100-1965200800010001000023\&lng=en

David, Ricardo Santos. 2017. "Formação de professores para o ensino superior: docência na contemporaneidade”. Periferia: Educação, cultura e inovação 9 (2): 1-20. www.e-publicacoes.uerj.br/index.php/periferia/article/download/28880/22118

Demo, Pedro. 2001. Pesquisa: princípio científico e educativo. 8. ed. São Paulo: Cortez.

Emmel, Rúbia e Alexandre José Krul. 2017. "A docência no Ensino Superior: reflexões e perspectivas”. Revista Brasileira de Ensino Superior 3 (1): 42-55. https://seer.imed.edu.br/index.php/REBES/article/view/1732/1231 
Figueiredo, Marco Aurélio Castro e Renato Rocha Souza. 2007. "Aspectos profissionais do bibliotecário". Encontros Bibli: Revista Eletrônica de Biblioteconomia e Ciência da Informação 24 (1): 10-31.

https://periodicos.ufsc.br/index.php/eb/article/viewFilele/1518-2924.2007v12n24p10/407

Freire, Paulo. 2001. "Carta de Paulo Freire aos professores". Estudos Avançados 15 (42): 259-268.

https://www.revistas.usp.br/eav/article/viewFile/9805/11377

Freire, Paulo. 2006. Pedagogia da autonomia: saberes necessários à pratica educativa. 33. ed. São Paulo: Paz e Terra.

Garcia, Rosineide Pereira Mubarack e Neilton da Silva. 2017. "Docência universitária integradora saberes e práticas compartilhadas na Licenciatura em Biologia da UFRB”. Revista Saberes Universitários 2 (1): 70-80.

http://www.sbu.unicamp.br/seer/ojs/index.php/saberes/article/view/8225/4514

Gil, Antonio Carlos. 2010. Como elaborar projetos de pesquisa. 5. ed. São Paulo: Atlas.

Goldenberg, Mirian. 1999. A arte de pesquisar: como fazer pesquisa qualitativa em Ciências Sociais. Rio de Janeiro: Record.

Junges, Kelen dos Santos e Marilda Aparecida Behrens. 2015. "Prática docente no Ensino Superior: a formação pedagógica como mobilizadora de mudança”. Perspectiva 33 (1): 285-317.

Marinho-Araujo, Claisy Maria e Mauro Luiz Rabelo. 2015. “Avaliação educacional: a abordagem por competências”. Avaliação 20 (2): 443-466. http://www.scielo.br/pdf/aval/v20n2/1414-4077-aval-20-02-00443.pdf

Pereira, Elisabete Monteiro de Aguiar. 2015. "Docência na universidade ultrapassa preparação para mundo do trabalho". Ensino Superior 1 (1): 1-6. https://www.revistaensinosuperior.gr.unicamp.br/artigos/docencia-na-universidade-ultrapassa-preparacao-para-mundo-do-trabalho

Rodrigues, Ana Vera Finardi e Izabel Mello Crespo. 2006. "Fonte de informação eletrônica: o papel do bibliotecário de bibliotecas universitárias”. Revista Digital de Biblioteconomia e Ciência da Informação 4 (1): 1-18.

http://www.sbu.unicamp.br/seer/ojs/index. php/rbci/article/view/348/230

Severino, Antônio Joaquim. 2008. Ensino e pesquisa na docência universitária: caminhos para a integração. São Paulo: USP.

Tomaél, Maria Inês. 2008. Fontes de informação na internet. Londrina: EDUEL.

Tomaél, Maria Inês e Marta Lígia Pomim Valentim. 2004. Avaliação de fontes de informação na Internet. Londrina: EDUEL.

Para citar este texto:

Santa Anna, Jorge. 2020. "Docência universitária na formação de profissionais dinâmicos: ampliando o potencial da profissão em biblioteconomia”. Investigación Bibliotecológica: archivonomía, bibliotecología e información 34 (82): 13-28.

http://dx.doi.org/10.22201/iibi.24488321xe.2020.82.58075 